\title{
Oxadiazole-2-oxides may have other functional targets, in addition to SjTGR, through which they cause mortality in Schistosoma japonicum
}

Li-Jun Song ${ }^{1,2+}$, Huan Luo ${ }^{3 \dagger}$, Wen-Hua Fan ${ }^{3+}$, Gu-Ping Wang ${ }^{3}$, Xu-Ren Yin ${ }^{1,2}$, Shuang Shen ${ }^{1,2}$, Jie Wang ${ }^{1,2}$, Yi Jin $^{1,2}$, Wei Zhang ${ }^{1,2}$, Hong Gao ${ }^{1,2}$, Qian Liu ${ }^{1,2}$, Wen-Long Wang ${ }^{3}$, Bainian Feng ${ }^{3 *}$ and Chuan-Xin Yu ${ }^{1,2,4^{*}}$

\begin{abstract}
Background: Schistosomiasis is one of the world's major public health problems. Besides praziquantel (PZQ), there is currently no other effective treatment against schistosomiasis. The development of new antischistosomal agents to curb the emergence of PZQ resistance should be a high priority. Oxadiazole-2-oxides have been identified as potential antischistosomal reagents, with thioredoxin glutathione reductase (TGR) being one of their molecular targets.

Methods: To develop novel treatment reagents against Schistosoma japonicum, 30 novel oxadiazole-2-oxides were synthesised and their antischistosomal activities on juvenile and adult S. japonicum were evaluated in vitro and in vivo. Their inhibitory activities against S. japonicum thioredoxin glutathione reductase (SjTGR) were also analysed.

Results: Most of the oxadiazole-2-oxides showed good juvenile and adult S. japonica killing activities in vitro. However, the antischistosomal effects of these compounds were not positively correlated with either their inhibition of SjTGR, or with nitric oxide (NO) release. Compounds 4a, 4b, 7c, 13, 16 and 20 resulted in $87.7 \%$, $83.1 \%, 87.1 \%, 84.6 \%, 90.8 \%$ and $69.5 \%$, respectively, mortality in the adult worms, when used to treat infected mice at schistosomula stage. These mortality rates were similar to or higher than that of artemisinin. Furthermore, compounds $4 a$ and 16 resulted in $66.7 \%$ and $69.4 \%$ reductions in the worm burdens, respectively, when infected mice were treated at the adult worm stage. These treatment effects were similar to PZQ. No differences in activity of the oxadiazole-2-oxides against female and male adult worms were observed. The toxicity of the oxadiazole-2-oxides on mammalian cells appeared to be similar to, or less than, that of PZQ.

Conclusions: The antischistosomal activity of the oxadiazole-2-oxides does not depend on NO production or the inhibition of SJTGR activity. There may be other functional targets of the oxadiazole-2-oxides in S. japonicum. Several of the novel oxadiazole-2-oxides synthesised in this study could be used to develop novel antischistosomal drugs and explore potential molecular targets.
\end{abstract}

Keywords: Schistosoma japonicum, Oxadiazole-2-oxide, Antischistosomal activity, Structure-activity relationship (SAR)

\footnotetext{
* Correspondence: fengbainian@jiangnan.edu.cn; chxnyu@163.com

${ }^{\dagger}$ Equal contributors

${ }^{3}$ School of Pharmaceutical Science, Jiangnan University, Wuxi 214122, China

${ }^{1}$ Key Laboratory on Technology for Disease Prevention and Control, Ministry

of Health, Jiangsu Provincial Key laboratory of Parasite Molecular Biology,

Jiangsu Institute of Parasitic Diseases, Wuxi, Jiangsu 214064, China

Full list of author information is available at the end of the article
} 


\section{Background}

Schistosomiasis is one of the most prevalent parasitic diseases. It has been estimated that 779 million people are at risk of infection worldwide [1]. The infection is caused by trematodes of the genus Schistosoma, among which Schistosoma mansoni, S. haematobium, S. japonicum, S. mekongi and S. intercalatum represent the most important pathogenic species for human beings. Depending on the species, the worms (schistosomes) persist in the liver and hepatic portal system or the urinary tract system of humans. Mature schistosomes lay eggs within their host, which often get trapped in the host's tissues, resulting in inflammatory and obstructive diseases of the affected organs [2]. In China, the disease caused by $S$. japonica is a major public health concern, with more than 280 thousand people infected [3]. To cure subtle morbidity and prevent the development of severe chronic stage hepatosplenomegaly, praziquantel (PZQ) is the only choice of chemotherapy. The drug has been widely used for more than three decades and is therefore susceptible to the emergence of praziquantelresistant schistosomes [4]. In addition, the mechanism by which PZQ works is still undefined [5].

A number of recent studies have attempted to modify PZQ [6-12], explore new chemical entities from natural products [13] and identify additional drug targets for the chemotherapy of schistosomiasis [14-18]. Oxadiazole-2oxides were identified as new drug leads against $S$. mansoni, while thioredoxin glutathione reductase (TGR) was found to be a potential molecular target of the oxadiazole2 -oxides $[15,16]$. Previously, we have shown that $S$. japonicum TGR (SjTGR) plays an essential role in maintaining the redox balance in S. japonicum and confirmed SjTGR as a potential target for the development of new drugs against schistosomiasis [18].

To our knowledge, few data have been reported for oxadiazole-2-oxides against S. japonicum [16]. We designed and synthesised novel oxadiazole-2-oxides to target SjTGR. The results show that some novel oxadiazole-2oxides had a good killing activity against $S$. japonicum, but did not inhibit the activity of SjTGR, implying that oxadiazole-2-oxides may have other functional targets in S. japonicum.

\section{Methods}

\section{Reagents}

5,5'-Dithiobis-(2-nitrobenzoic acid) (DTNB) and $\beta$ nicotinamide adenine dinucleotide 2'-phosphate reduced tetrasodium salt (NADPH) were purchased from Roche (Basel, Switzerland). RPMI 1640 and fetal bovine serum were from Gibco (Invitrogen Corporation, Carlsbad, USA). 3-(4,5-dimethyl-2-thiazolyl)-2,5-diphenyl-2-H-tetrazolium bromide (MTT), dimethyl sulfoxide (DMSO) and PZQ were sourced from Sigma-Aldrich Inc. (Saint Louis,
USA). The Nitric Oxide Assay Kit and 2-(4-carboxyphenyl)-4,4,5,5-tetramethylimidazoline-1-oxyl-3-oxide (carboxy-PTIO) came from Beyotime Biotechnology Corporation (Shanghai, China). Ethylenediaminetetraacetic acid (EDTA) and 2-[4-(2-hydroxyethyl)-1-piperazinyl]ethanesulfonic acid (HEPES) were purchased from Sangon Biotech Co. Ltd. (Shanghai, China), and artemisinin (AS) was purchased from Zelang Medical Technology Co. Ltd. (Nanjing, China).

\section{Parasites and experimental animals}

Infected Oncomelania hupensis, provided by the Department of Snail Biology, Jiangsu Institute of Parasitic Diseases, were incubated at $25-28{ }^{\circ} \mathrm{C}$, under illumination, for $2 \mathrm{~h}$ to hatch $S$. japonicum cercariae. The cercariae were collected from the water surface with clean cover glass and placed into a centrifuge tube using pre cooled RPMI 1640. Centrifugation was performed for $1 \mathrm{~min}$ at $1500 \mathrm{rpm}$, and then the steps above were repeated. After centrifugation, the supernatant solution was removed. The cercariae at the bottom were washed twice and resuspended with RPMI 1640. Approximately 20-30 cercariae ( $1 \mathrm{~mL}$ of the resuspension medium) were added to one well in a 24-well culture plate. They were incubated overnight at $37{ }^{\circ} \mathrm{C}$ with $5 \% \mathrm{CO}_{2}$. The survival rates and number of tails shed were observed under an inverted microscope. Cercariae that had shed their tails were used as juvenile S. japonicum [19, 20].

ICR mice (20-22 g), were obtained from the Shanghai Sub-Center of Experimental Animals, Chinese Academy of Sciences. They were maintained at the Department of Experimental Animals, Jiangsu Institute of Parasitic Diseases. To infect each mouse, its abdominal skin was exposed to $50 \mathrm{~S}$. japonica cercariae. All of the mice were executed to collect $S$. japonica adult worms, through portal vein perfusion, 35 days post-infection [21]. The adult $S$. japonica collected were washed with RPMI 1640 medium and then kept in RPMI 1640 medium ( $\mathrm{pH} 7.5$ ) with HEPES $20 \mathrm{mM}$, penicillin (100 IU/mL), streptomycin $(100 \mathrm{mg} / \mathrm{mL})$ and $10 \%$ fetal bovine serum [22]. Then, two pairs of adult worms were transferred into each well of a 24-well culture plate, with $2 \mathrm{~mL}$ of the same medium. The worms were cultured at $37{ }^{\circ} \mathrm{C}$ in a humid atmosphere with $5 \% \mathrm{CO}_{2}$.

\section{Synthesis of oxadiazole-2-oxide derivatives}

Compounds $4 \mathbf{a}-\mathbf{4 c}, 7 \mathbf{a}-7 \mathbf{c}$ and $\mathbf{8}$ were prepared using a protocol similar to that reported by the Maloney group (Scheme 1) [15]. To make compounds 9-21 (Scheme 2), compound $\mathbf{8}$ was coupled with various bromides in the presence of $\mathrm{Cs}_{2} \mathrm{CO}_{3}$, with yields of 40-60\%. For compound 22, compound $7 \mathbf{b}$ was treated with N-bromosuccinimide (NBS) and azodiisobutyronitrile (AIBN) in $\mathrm{CCl}_{4}$, obtaining a yield of $54 \%$. Then, 


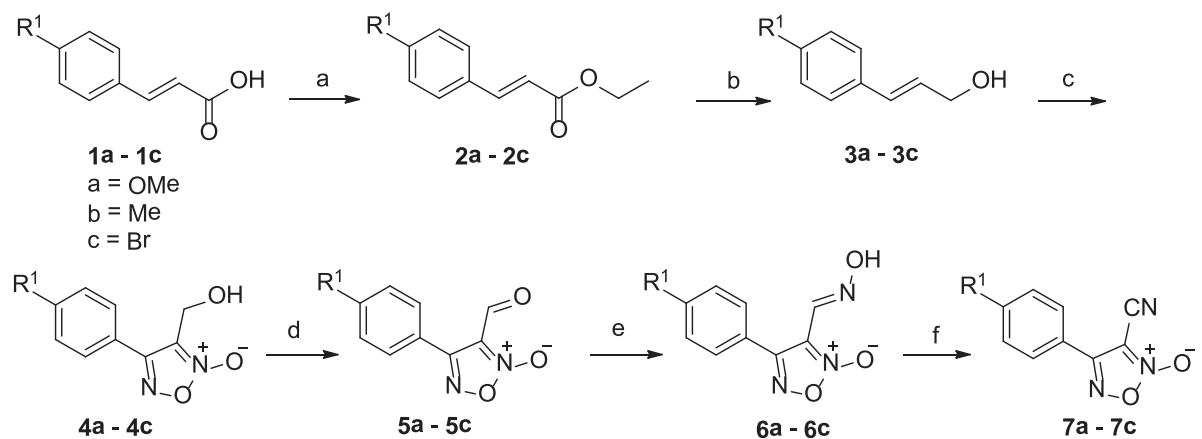

Scheme 1 Synthesis of compounds $\mathbf{4 a - 4 c}$ and $\mathbf{7 a}-\mathbf{7 c}$. Reagents and conditions: (a) $\mathrm{EtOH}, \mathrm{H}_{2} \mathrm{SO}_{4}$, reflux, overnight; (b) DIBAL-H, DCM, $\mathrm{N}_{2},-70{ }^{\circ} \mathrm{C}$ to rt, 12 h, 90-95 \%; (c) $\mathrm{NaNO}_{2}, \mathrm{HOAc}, \mathrm{H}_{2} \mathrm{O}, 0{ }^{\circ} \mathrm{C}$ to rt, 25-32 \%; (d) $\mathrm{MnO}_{2}, \mathrm{DCM}$, water-ice to rt, $4 \mathrm{~h}, 92 \%$; (e) $\mathrm{NH} \mathrm{H}_{4} \mathrm{OH}-\mathrm{HCl}$, pyridine, EtOH, $90{ }^{\circ} \mathrm{C}$, $3 \mathrm{~h}, 49 \%$; (f) $\mathrm{SOCl}_{2}, \mathrm{DMF}, \mathrm{N}_{2}, 30^{\circ} \mathrm{C}, 12 \mathrm{~h}, 70-75 \%$

compound 22 was coupled with various aromatic alcohols, using $\mathrm{Cs}_{2} \mathrm{CO}_{3}$ as the base in DMF, to give compounds 23-30, the yields of which varied from 25 to $45 \%$. The procedures for the preparation of compounds are detailed in Additional file 1.

\section{Oxadiazole-2-oxides inhibition of recombinant SjTGR}

The purified recombinant SjTGR proteins were produced according to the method described by Song et al. [18]. The inhibition of TrxR activity by the recombinant SjTGR was performed as reported by Rai et al. [15]. Briefly, $50 \mathrm{nM}$ SjTGR and $1 \mathrm{mM}$ NADPH were incubated with different concentrations of oxadiazole-2oxides $(2,4,6,10,20 \mu \mathrm{M})$ for $15 \mathrm{~min}$ at room temperature. Then, potassium phosphate buffer ( $\mathrm{pH}$ 7.4) containing $10 \mathrm{mM}$ EDTA, $100 \mu \mathrm{M}$ NADPH, and $3 \mathrm{mM}$ DTNB was added to start the reaction. The increase of absorbance at $412 \mathrm{~nm}$ was monitored during the first $2 \mathrm{~min}$. All assays were done in triplicate. Assays with no inhibition were performed as the control treatment. The $50 \%$ inhibitory concentration $\left(\mathrm{IC}_{50}\right)$ values of the oxadiazole-2-oxides were calculated by curve fitting, using SPSS 13.0 statistical software.

\section{Detection of nitric oxide (NO) release}

The release of nitric oxide (NO) was measured as previously reported [16]. Briefly, $15 \mathrm{nM} \mathrm{SjTGR,} \mathrm{with} \mathrm{or} \mathrm{with-}$ out $100 \mu \mathrm{M}$ NADPH or $5 \mathrm{mM}$ cysteine, was incubated at room temperature with $10 \mu \mathrm{M}$ of the oxadiazole-2- oxides for $50 \mathrm{~min}$. The NO release was detected according to the instructions of the Nitric Oxide Assay Kit, with the absorbance being measured at $540 \mathrm{~nm}$. The NO release of sodium nitrite, as a standard substance, was also measured. The values of NO release were calculated on the basis of the regression line plotted for the NO release from sodium nitrite. Each reaction was done in triplicate and the data presented are the average of three independent experiments.

Healthy S. japonica adult worms were collected as described above and homogenized in $0.1 \mathrm{M}$ potassium phosphate $(\mathrm{pH}$ 7.4). The homogenates were centrifuged at $20,000 \mathrm{~g}$ for $1 \mathrm{~h}$ at $4{ }^{\circ} \mathrm{C}$ and the supernatants were assayed for $\mathrm{NO}$ release. In addition, the worm homogenates $(100 \mu \mathrm{g})$ were incubated with $10 \mu \mathrm{M}$ oxadiazole-2-oxides for $50 \mathrm{~min}$ at room temperature and the production of $\mathrm{NO}$ was detected as above. Each reaction was done in triplicate.

\section{Cytotoxicity assay of oxadiazole-2-oxides on Hela cells}

Cytotoxicity assays were performed using Hela cells. Cells in the exponential growth phase were collected by centrifugation and a concentration of $4-5 \times 10^{4} / \mathrm{mL}$ was created. $100 \mu \mathrm{L}$ of the cell suspension was added to each well of a 96-well plate and cultured overnight at $37^{\circ} \mathrm{C}$ in a humid atmosphere with $5 \% \mathrm{CO}_{2}$. Oxadiazole-2-oxides (at 10, 20, 40, 80 and $160 \mu \mathrm{M}$ ) were added. Each concentration was assayed in triplicate, and control wells (no cells and no drugs) were assayed at the same time. The

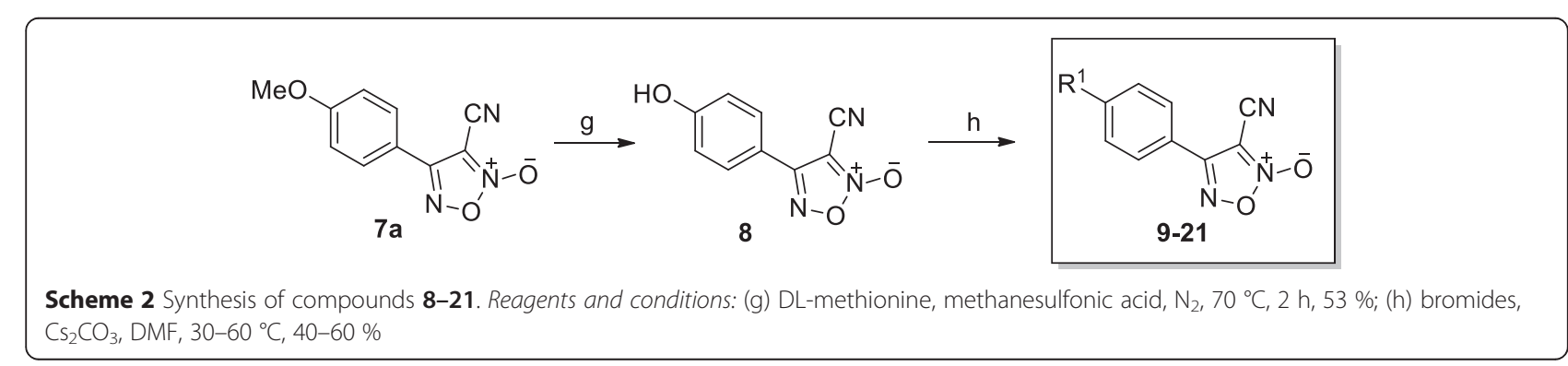


"no cell" control wells only contained RPMI 1640 medium, MTT, DMSO, and oxadiazole-2-oxides. The "no drug" control wells contained the Hela cells, RPMI 1640 medium, MTT and DMSO. The cells were cultured for $48 \mathrm{~h}$ at $37{ }^{\circ} \mathrm{C}$ in a humid atmosphere with $5 \% \mathrm{CO}_{2}$. Then, $20 \mu \mathrm{L}$ of $5 \mathrm{mg} / \mathrm{mL}$ MTT was added to each well and the culture conditions were maintained for $4 \mathrm{~h}$. After this point, the medium was removed and $150 \mu \mathrm{L}$ DMSO was added into each well to dissolve any crystallisation. The value of absorbance at $570 \mathrm{~nm}$ of each well was measured (at $570 \mathrm{~nm}$ ) with a microplate reader to assess the toxic effect of the oxadiazole-2-oxides on the vertebrate cells.

Toxicity of oxadiazole-2-oxides on juvenile and adult $S$. japonica in vitro

Oxadiazole-2-oxides $(10 \mu \mathrm{mol})$ were dissolved in $1 \mathrm{~mL}$ DMSO to prepare stock solutions, which were kept cold and in the dark. Working solutions were prepared prior to use at the appropriate dilutions, using RPMI 1640 medium.

20-30 juvenile worms were transferred into each well of a 24-well culture plate, containing $2 \mathrm{~mL}$ RPMI 1640 medium, $20 \mathrm{mM}$ HEPES, $100 \mathrm{IU} / \mathrm{mL}$ penicillin, $100 \mathrm{mg} /$ $\mathrm{mL}$ streptomycin and $10 \%$ fetal bovine serum. Then, oxadiazole-2-oxides $(2,5,10$, and $50 \mu \mathrm{M})$, diluted with the RPMI 1640 medium, were added to their allocated wells. The worms in the negative control wells were treated with equal volumes of RPMI 1640 or DMSO and worms treated with AS were observed as positive controls. The juvenile worms' survival rates were observed under an inverted phase contrast microscope (Leica, Wetzlar, Germany) at 24, 48 and 72 h. Parasite death was defined as an unclear internal structure of the juvenile worms, with incomplete tegument and contents overflowing radially, or unclear internal structure with complete tegument, but having no motor activity during $1 \mathrm{~min}$ of continuous observation [23]. All assays were repeated three times.

Adult worms were cultured in a 24-well culture plate for $30-60 \mathrm{~min}$ at $37{ }^{\circ} \mathrm{C}$, in a humid atmosphere with $5 \% \mathrm{CO}_{2}$. Then, oxadiazole-2-oxides at different concentrations $(10,25,50,100 \mu \mathrm{M})$ were added. Equal volumes of RPMI 1640 or DMSO were applied as negative controls, while PZQ was applied as a positive control. The adult worm mobility and parasite survival rates were monitored using an inverted phase contrast microscope, at 24, 48 and $72 \mathrm{~h}$. Parasite death was defined as there being no motor activity during 2 min of continuous observation, and morphological and tegumental alterations [24]. All assays were repeated three times.

To assess the importance of NO production, the potassium salt of carboxy-PTIO, a NO scavenger, was dissolved in water and $100 \mathrm{mM}$ was incubated with freshly perfused adult $S$. japonica in the presence or absence of $10 \mathrm{mM}$ oxadiazole-2-oxides. The worms' mobility, tegumental alterations and parasite survival were monitored using an inverted microscope. The experiment was done in triplicate.

\section{Oxadiazole-2-oxides treating S. japonica in vivo}

The abdominal skin of each mouse (ICR, female, 22$24 \mathrm{~g}$ ) was exposed to $20 \mathrm{~S}$. japonica cercariae (as described above). The mice were intraperitoneally injected with $10 \mathrm{mg} / \mathrm{kg}$ oxadiazole-2-oxides daily for 5 days, beginning either 7 or 35 days post-infection. Control mice were treated with $10 \mathrm{mg} / \mathrm{kg}$ of the carrier medium. All mice were sacrificed 42 days post-infection. The worm burden of each mouse was confirmed by counting the number of worms observed from a portal vein perfusion. The mouse livers were digested overnight with $5 \%$ potassium hydroxyl solution at $37{ }^{\circ} \mathrm{C}$ and the eggs in the liver tissue were counted under an inverted phase contrast microscope. The worm and egg reduction rates were calculated using the following formulas [18]:

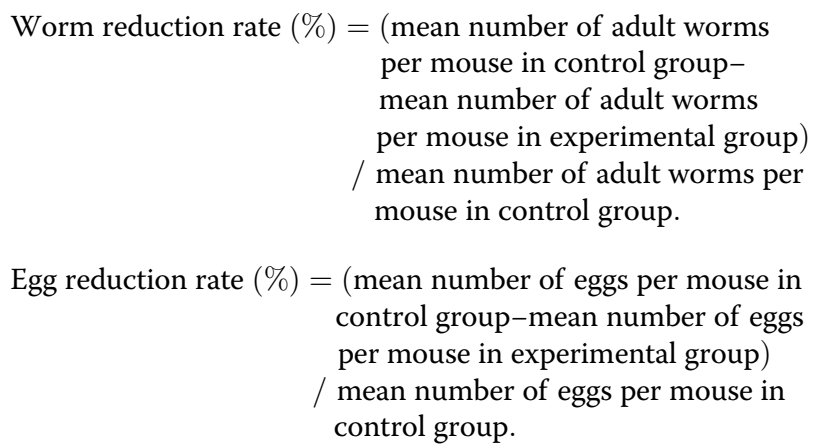

\section{Statistical analysis}

All data are given as the mean \pm standard deviation (SD). The worm and egg burden numbers after treatment with oxadiazole-2-oxides were statistically compared with the control, AS or PZQ groups using two-tailed Student's ttests. Differences in NO release from the oxadiazole-2oxides compared with control were similarly assessed. Cell survival rates after exposure to oxadiazole-2-oxides and PZQ, and worm survival rates after exposure to oxadiazole-2-oxides, with or without carboxy-PTIO, were determined using chi-square tests. SPSS 13.0 was used for the statistical analyses. Differences between mean values were considered to be significant at the level of $5 \%$.

\section{Ethical approval}

Ethical approval for the work performed was obtained from the Institutional Review Board (IRB00004221) of Jiangsu Institute of Parasitic Diseases, Wuxi, China (Permit Number: JIPDAERP20131120). All animals were housed in facilities and provided food and water 
conventionally. The infection, intraperitoneal injections and sacrifices (by carbon dioxide asphyxiation) were carried out according to recommendations in the Guidelines for the Care and Use of Laboratory Animals of the Ministry of Science and Technology of People's Republic of China ([2006]398). Suffering was minimised in accordance with the guidelines.

\section{Results}

Syntheses of oxadiazole-2-oxides and their inhibitory activities against SjTGR

Thirty oxadiazole-2-oxides were designed and synthesised following Schemes 1, 2, 3. The structures of these oxadiazole-2-oxides are detailed in Table 1 . The recombinant SjTGR was incubated with each oxadiazole-2oxide, and their respective inhibition on the TrxR activity of SjTGR was observed. The results showed that compounds $4 a, 4 b, 4 c, 7 a, 7 b, 7 c, 8,11,12,13,14,16$, 20 and 22 inhibited the activity of SjTGR (Fig. 1 and Table 1), with $\mathrm{IC}_{50}$ values between 0.5 and $37.4 \mu \mathrm{M}$. Compounds 9, 10, 15, 17, 18, 19, 21, 23, 24, 25, 26, 27, 28 and 29 did not inhibit the activity of SjTGR (Table 1).

\section{NO production of oxadiazole-2-oxides in vitro}

When the oxadiazole-2-oxides were incubated with cysteine at room temperature, compounds $7 \mathrm{c}, \mathbf{1 3}, \mathbf{1 6}, \mathbf{2 0}$, and 22 released $9.0 \pm 0.5,8.6 \pm 0.4,8.3 \pm 0.0,8.8 \pm 0.7$, and $9.0 \pm 0.1 \mu \mathrm{M}$ NO, respectively. The PBS and DMSO control wells produced $3.6 \pm 0.4$ and $3.2 \pm 0.5 \mu \mathrm{M}$ NO, respectively (Fig. 2). The difference in NO production between the above five compounds and DMSO was significant $(P<0.05)$. The other oxadiazole-2-oxides produced similar NO levels to the PBS and DMSO control wells (Fig. 2; $P>0.05$ ). Incubation of the oxadiazole-2oxides with SjTGR + NADPH, SjTGR alone or worm homogenate supernatant, also released similar NO to the PBS and DMSO controls $(P>0.05$; Additional file 2: Table S1).

\section{Cytotoxicity of oxadiazole-2-oxides on Hela cells}

The cytotoxicity assessment of the oxadiazole-2-oxides on the Hela cells was observed using the MTT method.
The viability of the Hela cells immersed in $80 \mu \mathrm{M}$ of PZQ for $72 \mathrm{~h}$ was $76 \%$, while those in $80 \mu \mathrm{M}$ of compounds $4 \mathbf{a}, \mathbf{4 b}, \mathbf{7 c}, \mathbf{1 3}, \mathbf{1 6}, 20$ after $72 \mathrm{~h}$ were $91 \%$, $96 \%, 66 \%, 80 \%, 89 \%$ and $87 \%$ viable, respectively. Except for compound $7 \mathrm{c}$, the toxicity of compounds $\mathbf{1 3}$, 4a, 4b, 20, and 16 to the Hela cells was similar to, or less than that of PZQ. The differences in toxicity were not significant, between the oxadiazole-2-oxides and PZQ $(P>0.05)$.

\section{Toxicity of oxadiazole-2-oxides to cultured juvenile and adult S. japonica}

The survival of juvenile and adult $S$. japonica, cultured in a medium, containing different concentrations of oxadiazole-2-oxides showed that, compared to AS - AS at $50 \mu \mathrm{M}$ resulted in the death of $51.3 \pm 5.1 \%$ juvenile worms after $24 \mathrm{~h}$ - compounds $4 \mathbf{b}, \mathbf{7 c}, \mathbf{9}, 22$ and 23 at $50 \mu \mathrm{M}$ increased mortality, to more than $70.0 \%$ after $24 \mathrm{~h}$. In contrast, compounds $4 \mathrm{c}, 7 \mathbf{a}, 8,12,13,16,17$, 21 and 28 (at $50 \mu \mathrm{M}$ ) did not affect the juvenile worms, with less than $30.0 \%$ mortality after $24 \mathrm{~h}$. Compared to PZQ, which, at $25 \mu \mathrm{M}$ resulted in the death of $25.0 \pm$ $7.8 \%$ adult worms after $24 \mathrm{~h}$, compounds $7 \mathbf{a}, 7 \mathbf{b}, 7 \mathbf{c}, \mathbf{1 2}$, 14, 18, 19, 22, 23, 24, 26 and 28 at $25 \mu \mathrm{M}$ increased mortality, to more than $75.0 \%$. Compounds $\mathbf{1 7}$ and $\mathbf{2 9}$ did not cause death in the adult worms after $24 \mathrm{~h}$, even at the maximum concentration tested $(100 \mu \mathrm{M})$. Interestingly, we found that compounds $4 a, 7 c, 13,16$ and 20 displayed killing activities to both the juvenile and adult worms of S. japonica. At concentrations of $50 \mu \mathrm{M}$, compounds $7 \mathrm{c}, \mathbf{1 3}$ and $\mathbf{1 6}$ resulted in $100.0 \pm 0.0 \%$ mortality of adult worms within $24 \mathrm{~h}$, and $100.0 \pm 0.0 \%$, $41.0 \pm 6.3 \%$ and $72.1 \pm 3.7 \%$ mortality of juvenile worms after $72 \mathrm{~h}$, respectively. $100 \mu \mathrm{M}$ of compounds $\mathbf{4 a}, 20$ caused $100.0 \pm 0.0 \%$ of the adult worms to die, and 90.0 $\pm 2.8 \%$ and $67.6 \pm 4.5 \%$ of the juvenile worms died in $72 \mathrm{~h}$, respectively. $100 \mu \mathrm{M}$ of compound $4 \mathrm{~b}$ resulted in $57.1 \pm 2.1 \%$ adult worm death at $24 \mathrm{~h}, 100.0 \pm 0.0 \%$ adult worm mortality after $48 \mathrm{~h}$, and $100.0 \pm 0.0 \%$ juvenile mortality at $72 \mathrm{~h}$. The killing activities against the juvenile and adult worms of these 7 compounds increased with concentration and time (Additional file 3: Tables S2 and Additional file 4: Table S3, Fig. 3a, b, c, d).

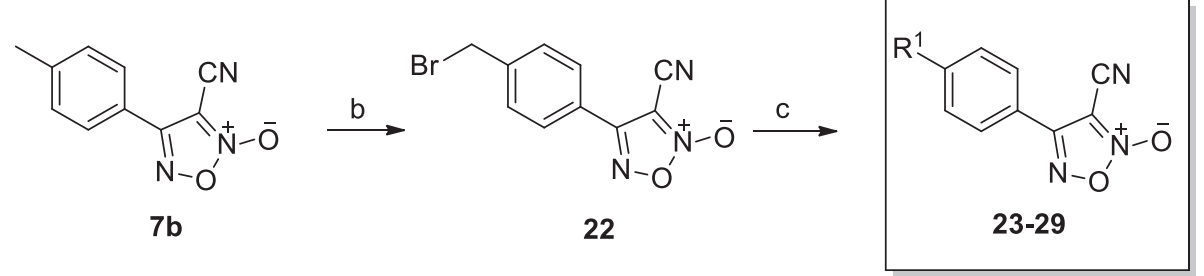

Scheme 3 Synthesis of compounds 22-30. Reagents and conditions: (b) NBS, AlBN, $\mathrm{CCl}_{4}, 80{ }^{\circ} \mathrm{C}$, overnight, 54 \%; (c) aromatic alcohols, or $\mathrm{Cs}_{2} \mathrm{CO}_{3}$, DMF, $30-60{ }^{\circ} \mathrm{C}, 25-45 \%$ 
Table 1 Structures of the oxadiazole-2-oxides and their inhibitory activities against SjTGR

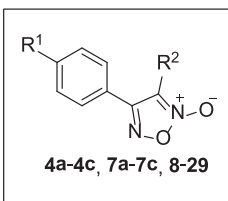

\begin{tabular}{|c|c|c|c|}
\hline Comp & $\mathrm{R}^{1}$ & $\mathrm{R}^{2}$ & $\mathrm{IC}_{50}$ of $\mathrm{SjTGR}^{\mathrm{a}}(\mu \mathrm{M})$ \\
\hline Vehicle & & & $\mathrm{NA}^{\mathrm{b}}$ \\
\hline $\mathbf{A S}$ & & & $\mathrm{NA}^{\mathrm{b}}$ \\
\hline PZQ & & & $\mathrm{NA}^{\mathrm{b}}$ \\
\hline $4 a$ & $\mathrm{MeO}$ & $\mathrm{CH}_{2} \mathrm{OH}$ & 2.7 \\
\hline $4 b$ & $\mathrm{Me}$ & $\mathrm{CH}_{2} \mathrm{OH}$ & 1.7 \\
\hline $4 c$ & $\mathrm{Br}$ & $\mathrm{CH}_{2} \mathrm{OH}$ & 8.6 \\
\hline $7 a$ & $\mathrm{MeO}$ & $\mathrm{CN}$ & 12.2 \\
\hline $7 b$ & $\mathrm{CH}_{3}$ & $\mathrm{CN}$ & 14.2 \\
\hline $7 \mathrm{c}$ & $\mathrm{Br}$ & $\mathrm{CN}$ & 3.7 \\
\hline 8 & $\mathrm{OH}$ & $\mathrm{CN}$ & 37.4 \\
\hline 9 & & $\mathrm{CN}$ & $\mathrm{NA}^{\mathrm{b}}$ \\
\hline 10 & & $\mathrm{CN}$ & 89.2 \\
\hline 11 & & $\mathrm{CN}$ & 23.0 \\
\hline 12 & $\mathrm{Br} \frown \mathrm{O}_{-}$ & $\mathrm{CN}$ & 21.7 \\
\hline 13 & & $\mathrm{CN}$ & 1.6 \\
\hline 14 & 20 & $\mathrm{CN}$ & 15.5 \\
\hline 15 & No. & $\mathrm{CN}$ & $\mathrm{NA}^{\mathrm{b}}$ \\
\hline 16 & a. & $\mathrm{CN}$ & 0.5 \\
\hline 17 & & $\mathrm{CN}$ & $\mathrm{NA}^{\mathrm{b}}$ \\
\hline 18 & & $\mathrm{CN}$ & $\mathrm{NA}^{\mathrm{b}}$ \\
\hline 19 & & $\mathrm{CN}$ & $\mathrm{NA}^{\mathrm{b}}$ \\
\hline 20 & & $\mathrm{CN}$ & 3.3 \\
\hline 21 & & $\mathrm{CN}$ & $\mathrm{NA}^{\mathrm{b}}$ \\
\hline 22 & $\mathrm{BrCH}_{2}$ & $\mathrm{CN}$ & 9.7 \\
\hline 23 & & $\mathrm{CN}$ & $\mathrm{NA}^{\mathrm{b}}$ \\
\hline 24 & & $\mathrm{CN}$ & $\mathrm{NA}^{\mathrm{b}}$ \\
\hline 25 & & $\mathrm{CN}$ & $\mathrm{NA}^{\mathrm{b}}$ \\
\hline 26 & & $\mathrm{CN}$ & $\mathrm{NA}^{\mathrm{b}}$ \\
\hline 27 & & $\mathrm{CN}$ & $\mathrm{NA}^{\mathrm{b}}$ \\
\hline 28 & & $\mathrm{CN}$ & $\mathrm{NA}^{\mathrm{b}}$ \\
\hline 29 & & $\mathrm{CN}$ & $\mathrm{NA}^{\mathrm{b}}$ \\
\hline
\end{tabular}

${ }^{a}$ SjTGR enzymatic assay

b No activity
There was no statistically significant difference in mortality due to the sex of the worms, among the seven compounds (Fig. 3e). When a NO scavenger (carboxyPTIO) was added to the culture of adult worms in vitro, with compounds $\mathbf{7} \mathbf{c}$ and $\mathbf{1 6}$, there were no differences in the killing activities of the compounds (with or without carboxy-PTIO; $P>0.05$ ) (Fig. 4).

\section{The treatment effect of oxadiazole-2-oxides in vivo}

The results of treating the mice with the oxadiazole-2oxides in vivo showed that compounds $4 \mathbf{a}, \mathbf{4 b}, \mathbf{7 c}, \mathbf{1 3}$, 16 and 20 caused $87.7 \%, 83.1 \%, 87.1 \%, 84.6 \%, 90.8 \%$ and $69.5 \%$ mortality in the adult worms, respectively; and the eggs were reduced by $47.0 \%, 0 \%, 52.0 \%$, $52.6 \%, 49.5 \%$ and $3.3 \%$, respectively (when the mice were treated at the juvenile worm stage). There was a significant rise in the adult worm reduction rate of compound 16, compared to the AS group $(78.5 \%$ in worm burdens, $P<0.05$ ) (Table 2). Compounds $4 \mathbf{a}$ and 16 resulted in $66.7 \%$ and $69.4 \%$ reductions in the worms, respectively, and $3.8 \%$ and $20.0 \%$ reduction in the eggs, respectively (when the mice were treated at the adult worm stage). The treatment effect of compounds $4 \mathbf{a}$ and 16 were similar to that of PZQ (worm reduction rate was $72.3 \% ; P>0.05$ ). The other novel oxadiazole-2oxides tested appeared to not affect the adult worms (Table 3).

\section{Discussion}

For almost three decades, PZQ has been the only drug recommended by the World Health Organization to treat and control schistosomiasis, through mass drug administration (MDA) programs [25]. No vaccine has ever been developed [25]. PZQ does not guard against reinfection and is not effective against juvenile schistosomes. Furthermore, schistosome phenotypes are emerging that are resistant to PZQ chemotherapy, and PZQ has a limited effect on developed liver and spleen lesions [4, 26]. Although these issues have not led to treatment failures or the necessity to change control measures to date, it is imperative to develop new antischisosomal agents in anticipation of the potential threat.

Oxadiazole-2-oxides have been identified to inhibit the activity of TGR and kill $S$. mansoni worms during the in vivo treatment of schistosome-infected mice, which led to more than $90 \%$ reduction in the worm burdens [15, 16]. However, there has been little attention on the effect of the oxadiazole-2-oxides against $S$. japonica, a helminth endemic to Asia. We designed and synthesised 30 oxadiazole-2-oxides, on the basis of Schemes 1, 2, 3, and studied their killing activities against juvenile and adult $S$. japonica. The mechanisms of action of the oxadiazole-2-oxides were also explored. 


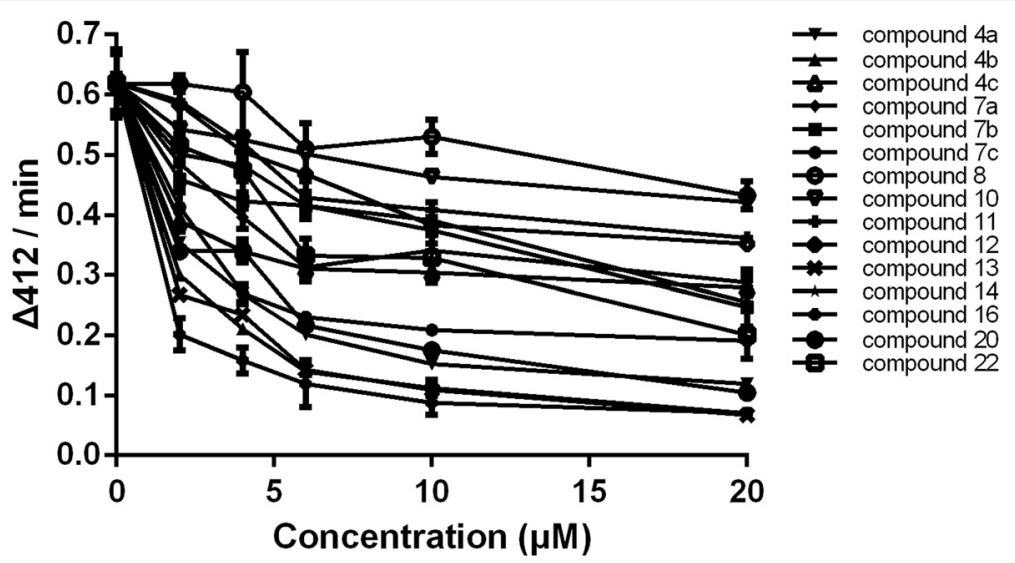

Fig. 1 Inhibition of recombinant SjTGR by oxadiazole-2-oxides. $50 \mathrm{nM} \mathrm{SjTGR}$ and $1 \mathrm{mM}$ NADPH were incubated with different concentrations of oxadiazole-2-oxides $(2,4,6,10,20 \mu \mathrm{M})$ for $15 \mathrm{~min}$ at room temperature. Then, potassium phosphate buffer (pH 7.4) containing $10 \mathrm{mM}$ EDTA, $100 \mu \mathrm{M}$ NADPH, $3 \mathrm{mM}$ DTNB was added to start the reaction. The increase in absorbance at $412 \mathrm{~nm}$ was monitored during the first 2 min. All assays were done in triplicate. Results shown are the mean \pm SD $(n=3)$

The in vitro antischistosomal activity on juvenile and adult S. japonica, as well as their inhibitory activity against SjTGR (assessed using our previously reported protocol [18]) showed (Table 1 and Additional file 3: Tables S2 and Additional file 4: Table S3) that compounds $7 \mathbf{a}-\mathbf{c}$ and $\mathbf{8}$ had the same structures as those described in the work with S. mansoni [15]. These compounds had good worm killing activity, resulting in $100.0 \pm 0.0 \%$, $83.3 \pm 4.7 \%, 70.0 \pm 7.1 \%$, and $71.4 \pm 0.9 \%$ mortality in the adult worms after $72 \mathrm{~h}$, at concentrations of $10 \mu \mathrm{M}$, respectively; these mortality levels are similar to the data

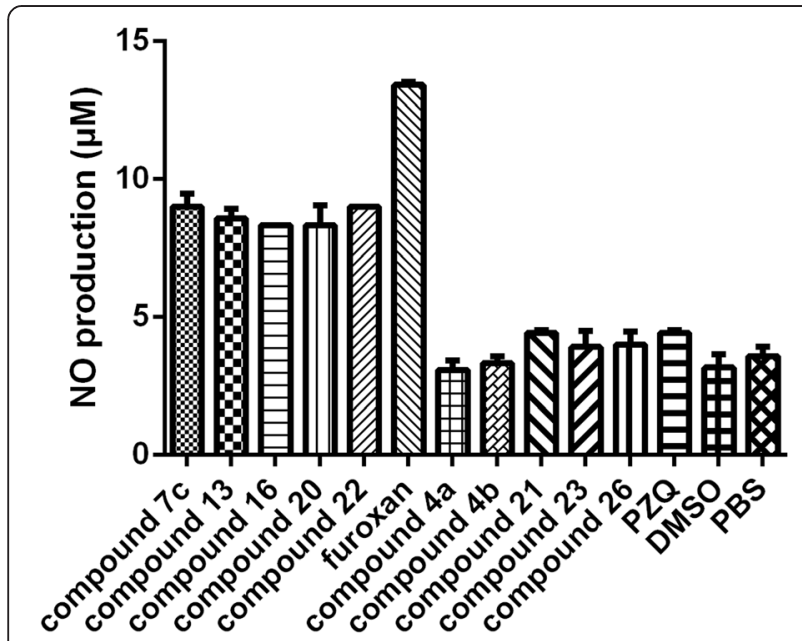

Fig. 2 Nitrogen orxide (NO) release from oxadiazole-2-oxides incubated in vitro. $15 \mathrm{nM}$ SjTGR, $100 \mu \mathrm{M}$ NADPH and $5 \mathrm{mM}$ cysteine were incubated with $10 \mu \mathrm{M}$ oxadiazole-2-oxides for $50 \mathrm{~min}$ at room temperature. The nitric oxide (NO) released was detected according to the NO Assay Kit (Beyotime Biotechnology Corporation). The NO release levels were calculated based on the regression line of sodium nitrite (standard). Each reaction was done in triplicate. Results shown are the mean $\pm \operatorname{SD}(n=3)$
(100.0 \%, $70.0 \%, 100.0 \%$, and $100.0 \%$, respectively) obtained using S. mansoni [15]. These data show that the oxadiazole-2-oxides may have the same pharmacology in both schistosome species.

Comparing compounds $\mathbf{4 a - 4 c}$ and $7 \mathbf{a}-7 \mathbf{c}$, the cyano group in compound $\mathbf{7} \mathbf{c}$ replaced the hydroxyl group in compound 4c, and at $100 \mu \mathrm{M}$, compound 4c caused $57.1 \pm 2.3 \%$ mortality while compound $7 \mathrm{c}$ caused 100.0 $\pm 0.0 \%$ mortality in the adult worms. When the hydroxyl group in compound $\mathbf{4 a}$ was changed into cyano group of compound $\mathbf{7 a}$, the activity against SjTGR slightly weakened (the $\mathrm{IC}_{50}$ values were $2.7 \mu \mathrm{M}$ and 12.2 $\mu \mathrm{M}$, respectively), but the worm killing activity of $7 \mathbf{a}$ was markedly enhanced. In contrast, compound $\mathbf{4 b}$ had both better activity against SjTGR and better worm killing activity, than $\mathbf{7 b}$. In compounds 9-11 the number of $\mathrm{CH}_{2}$ groups between the $\mathrm{O}$ atom and ester group increased, the corresponding SjTGR inhibitory effects increased, but the worm killing activity did not. Interestingly, compound 9, which had no SjTGR inhibitory activity, caused the best worm mortality of the three compounds. Among compounds 12-16, compounds 12, 13 and 14 caused moderate SjTGR inhibition and had good worm killing activities. Compound $\mathbf{1 5}$ did not inhibit SjTGR and exhibited similar worm killing activity at $10 \mu \mathrm{M}$ to compounds $\mathbf{1 2}, \mathbf{1 3}$ and $\mathbf{1 4}$. Changing the $\mathrm{C}-\mathrm{C}$ single bond (compound 15) into a double bond $(C=C$; compound 16), inhibited SjTGR at sub-micromolar concentrations $\left(\mathrm{IC}_{50}=0.54 \mu \mathrm{M}\right)$, but there was no change in activity against the parasite.

As for compounds 17-21, compound 18, with an isopentyloxy group, did not inhibit SjTGR, while compound 20 with a prop-2-yn-1-yloxy group inhibited SjTGR at low micromolar concentrations; these two compounds both killed $100.0 \pm 0.0 \%$ of worms in $72 \mathrm{~h}$, 


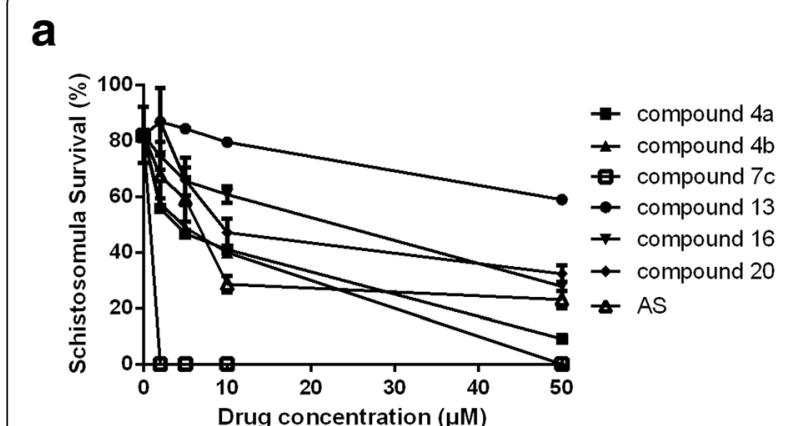

C

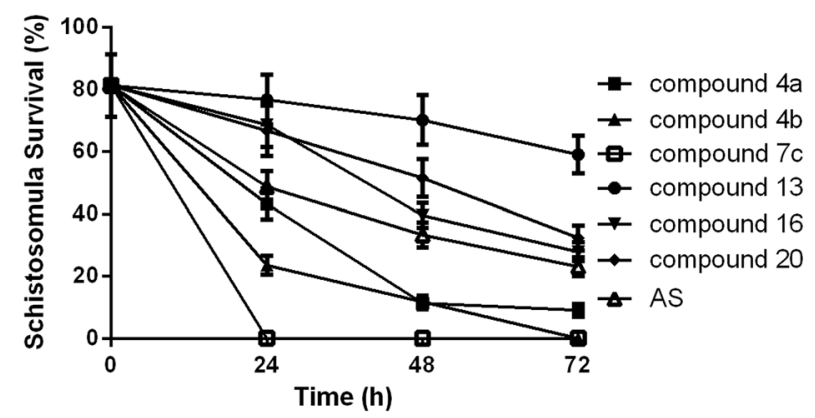

e

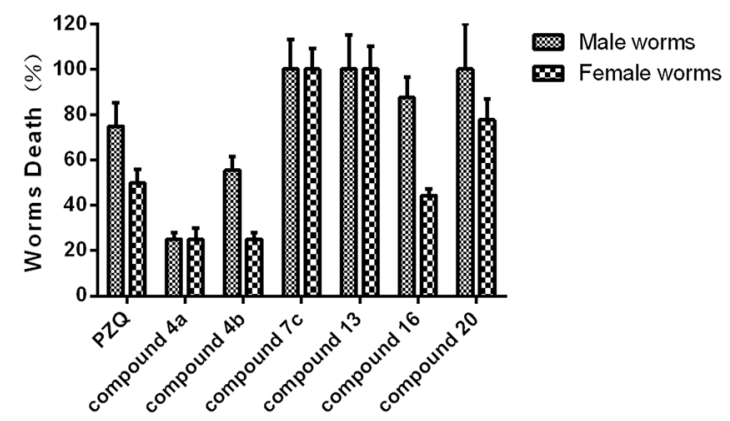

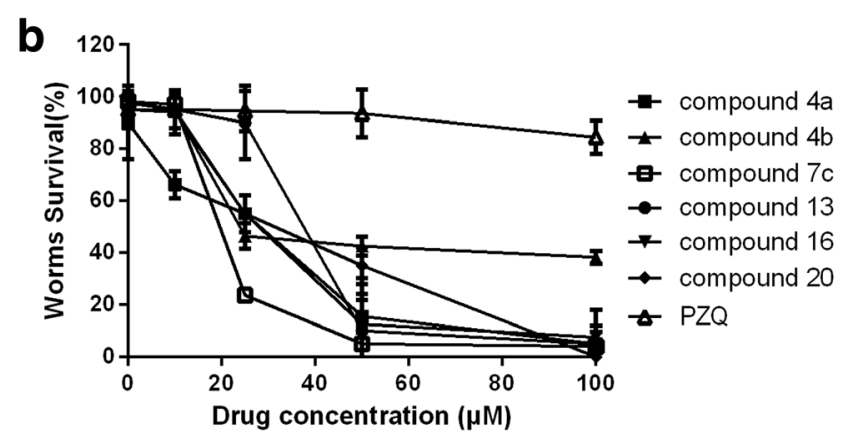

d

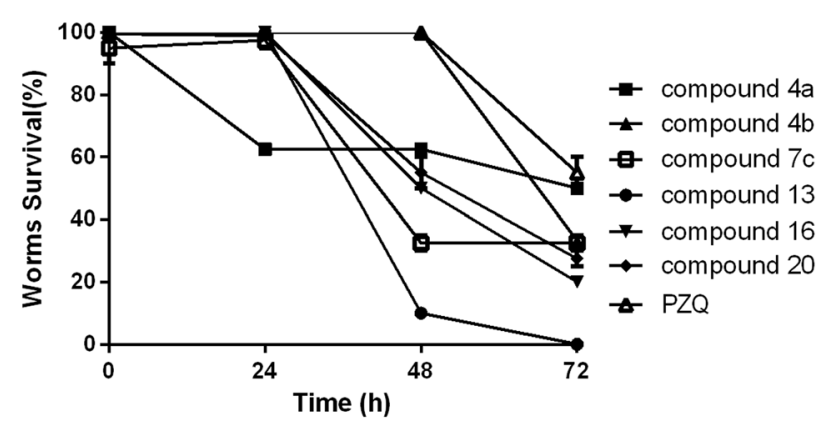

Fig. 3 Effects of oxadiazole-2-oxides on mortality of juvenile and adult S. japonica in vitro. Oxadiazole-2-oxides were applied at different concentrations and mortality was measured in the juvenile worms after $72 \mathrm{~h} \mathrm{(a)} \mathrm{and} \mathrm{adult} \mathrm{worms} \mathrm{after} 24 \mathrm{~h} \mathrm{(b).} \mathrm{In} \mathrm{c,} \mathrm{the} \mathrm{mortality} \mathrm{of} \mathrm{juvenile} \mathrm{S}$. japonica caused by the oxadiazole-2-oxides (50 $\mathrm{MM}$ ) at different exposure times is shown. In $\mathbf{d}$ the mortality of adult S. japonica caused by the oxadiazole-2-oxides (10 $\mu \mathrm{M}$ ) at different exposure times is shown. In e, the mortality of male and female adult specimens of S. japonica exposed to $8 \mu \mathrm{M}$ of oxadiazole-2-oxides after $120 \mathrm{~h}$ is shown

at concentrations of $25 \mu \mathrm{M}$. The symmetrical compound 21 did not inhibit SjTGR and exhibited slightly poorer worm killing activity than compound 13. Interestingly, compound 19, with a benzyloxy group, was the best at killing worms among all the compounds assessed. However, with a carbonyl group inserted between the phenyl group and carbon atom, compound $\mathbf{1 7}$ was poor at killing worms.

Among compounds 22-29, those with bulkier aromatic groups (compounds 27, 28 and 29) caused low mortality rates, compared with compound 19, which had a smaller phenyl group. In addition, compounds without substitution on the phenyl group (compounds
19 and 23) were better at killing the worms than those with substitution (compounds 24, 25 and 26). Except for compounds 25 and 29, the other oxadiazole-2-oxides caused higher worm mortality rates than PZQ. Compound 22 moderately inhibited SjTGR, and had a good worm killing activity; this indicates the worm killing activities of the oxadiazole-2-oxides were not directly correlated to their SjTGR inhibitory activities.

The results of the mice experiments showed large and highly significant reductions in worm burdens by treating the mice at juvenile worm stage with compounds $\mathbf{4 a}$, 4b, 7c, 13 and 16, compared to AS. The treatment effects of compounds $\mathbf{4 a}$ and $\mathbf{1 6}$ were almost the same as 


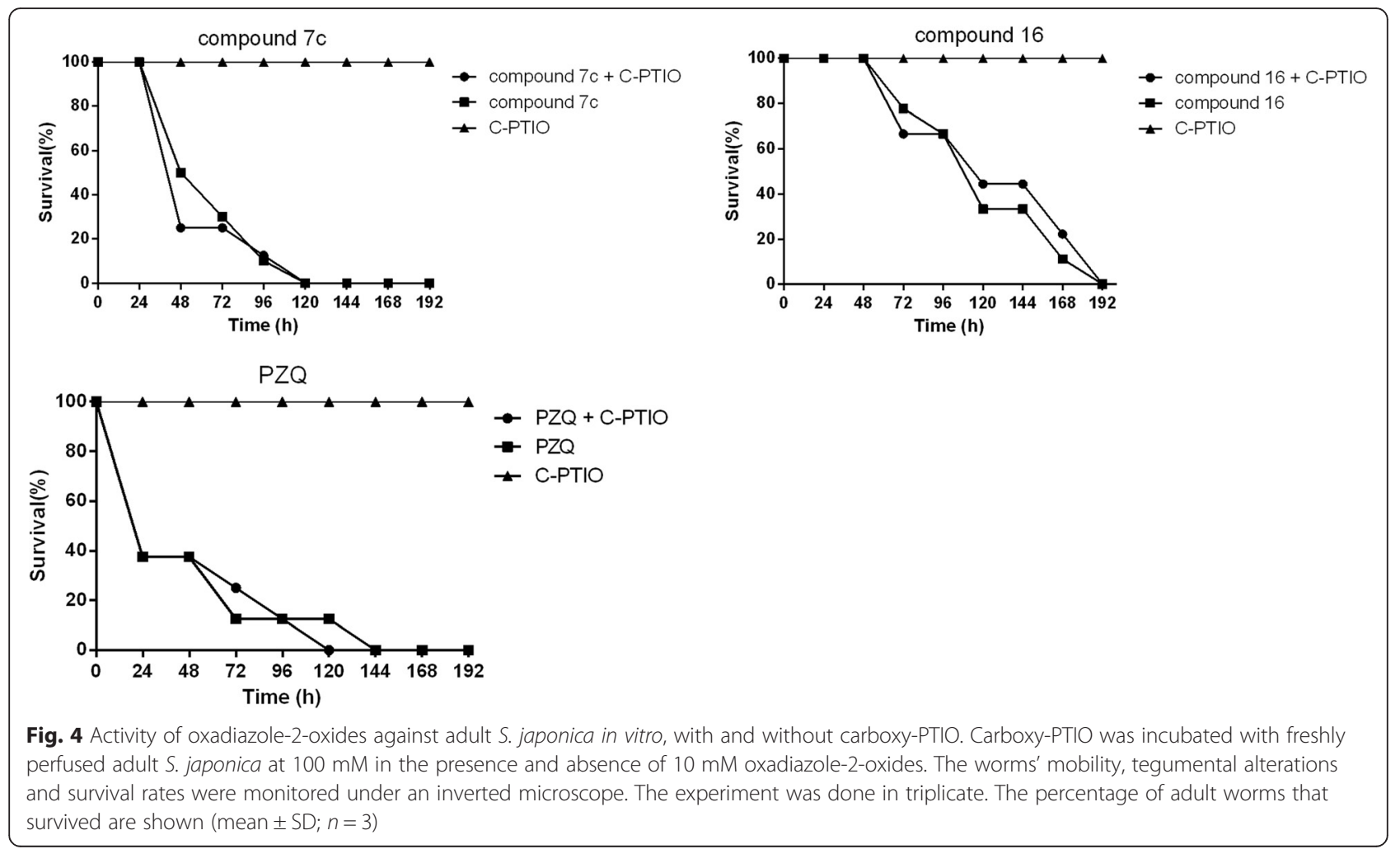

PZQ, at the adult worm stage. These results generally agree with Rai et al. [15], who reported that oxadiazole2-oxide derivatives nearly cured $S$. mansoni-infected mice, with a $90 \%$ reduction in the worm burdens. However, there was a contradiction between the worm and egg reduction rates in the PZQ and oxadiazole-2-oxides treatments for the mice; compounds $\mathbf{4 a}$ and $\mathbf{1 6}$ seemed to eliminate the adult parasites essentially to the same extent as PZQ, but had less effect on the egg burden than PZQ. The main reason was that the reductions in the female worms due to treatment with compounds $4 a$ and $\mathbf{1 6}$ were $36.8 \%$ and $44.7 \%$, which was less than the reduction in female worms due to PZQ treatment $(60.5 \%)$ (data not shown). This structure activity relationship (SAR) could have important implications for further drug development of the oxadiazole-2-oxides against schistosomiasis.

The oxadiazole-2-oxide core is a class of NO donating compounds [27]. NO is a free radical and is a wellstudied physiological signaling agent; it is best known for its ability to relax smooth muscle tissue, resulting in vasodilatation and increased blood flow at low concentrations [28]. However, elevated levels of $\mathrm{NO}$ can be toxic, which can kill normal cells, tumuor cells, bacteria and parasites [29-31]. Rai et al. [15] proposed that oxadiazole-2-oxides kill S. mansoni due to the free thiols of TGR, which can attack the oxadiazole-oxide, affecting its molecular arrangement and releasing of NO; they

Table 2 Treatment effects of oxadiazole-2-oxides on juvenile S. japonicum in mice

\begin{tabular}{llllll}
\hline Groups & Mice No. & $\begin{array}{l}\text { Number of worms } \\
\text { (Mean } \pm \text { SD) }\end{array}$ & Worm reduction rate (\%) & $\begin{array}{l}\text { Number of eggs per gram of liver } \\
\text { (Mean } \pm \text { SD) }\end{array}$ & Egg reduction rate (\%) \\
\hline Control & 7 & $10.8 \pm 0.8$ & & $8,032.9 \pm 2,192.1$ & $4,258.9 \pm 1,910.0\left(P>0.05^{* *}\right)$ \\
Compound 4a & 4 & $1.3 \pm 0.8\left(P>0.05^{* *}\right)$ & $87.7\left(P<0.01^{*}\right)$ & $47.0\left(P<0.05^{*}\right)$ \\
Compound 4b & 2 & $1.8 \pm 1.5\left(P>0.05^{* *}\right)$ & $83.1\left(P<0.01^{*}\right)$ & $8,669.2 \pm 2,255.8\left(P<0.05^{* *}\right)$ & - \\
Compound 7c & 2 & $1.4 \pm 0.8\left(P>0.05^{* *}\right)$ & $87.1\left(P<0.01^{*}\right)$ & $3,859.4 \pm 3,749.4\left(P>0.05^{* *}\right)$ & $52.0\left(P>0.05^{*}\right)$ \\
Compound 13 & 2 & $1.7 \pm 0.7\left(P>0.05^{* *}\right)$ & $84.6\left(P<0.01^{*}\right)$ & $3,808.9 \pm 1,288.9\left(P>0.05^{* *}\right)$ & $52.6\left(P<0.05^{*}\right)$ \\
Compound 16 & 5 & $1.0 \pm 0.5\left(P>0.05^{* *}\right)$ & $90.8\left(P<0.01^{*}\right)$ & $4,054.5 \pm 1,322.1\left(P>0.05^{* *}\right)$ & $49.5\left(P<0.01^{*}\right)$ \\
Compound 20 & 6 & $3.0 \pm 0.9\left(P<0.05^{* *}\right)$ & $69.5\left(P<0.01^{*}\right)$ & $7,767.5 \pm 2,676.6\left(P<0.05^{* *}\right)$ & $3.3\left(P>0.05^{*}\right)$ \\
AS & 4 & $2.3 \pm 1.0$ & $78.5\left(P<0.01^{*}\right)$ & $2,932.2 \pm 1,149.3$ & $63.5\left(P<0.01^{*}\right)$ \\
\hline
\end{tabular}

"Effect of compound versus control analysed by Student's t-test; ${ }^{* *}$ Effect of compound versus AS analysed by Student's t-test 
Table 3 Treatment effects of oxadiazole-2-oxides on adult S. japonicum in mice

\begin{tabular}{llllll}
\hline Groups & Mice No. & $\begin{array}{l}\text { Number of worms } \\
(\text { Mean } \pm \text { SD) }\end{array}$ & Worm reduction rate $(\%)$ & $\begin{array}{l}\text { Number of eggs per gram of liver } \\
\text { (Mean } \pm \text { SD) }\end{array}$ & Egg reduction rate (\%) \\
\hline Control & 7 & $12.0 \pm 2.1$ & $8032.9 \pm 2192.1$ & $7730.8 \pm 1457.8\left(P<0.05^{* *}\right)$ & $3.8\left(P>0.05^{*}\right)$ \\
Compound 4a & 4 & $4.0 \pm 2.5\left(P>0.05^{* *}\right)$ & $66.7\left(P<0.01^{*}\right)$ & $7007.8 \pm 2420.2\left(P<0.05^{* *}\right)$ & $12.8\left(P>0.05^{*}\right)$ \\
Compound 4b & 4 & $9.0 \pm 3.8\left(P<0.05^{* *}\right)$ & $25.0\left(P>0.05^{*}\right)$ & $7213.0 \pm 2658.0\left(P<0.05^{* *}\right)$ & $10.2\left(P>0.05^{*}\right)$ \\
Compound 7c & 6 & $12.0 \pm 3.9\left(P<0.05^{* *}\right)$ & - & $8201.4 \pm 2066.0\left(P<0.05^{* *}\right)$ & - \\
Compound 13 & 5 & $8.6 \pm 2.4\left(P<0.05^{* *}\right)$ & $28.3\left(P<0.05^{*}\right)$ & $6424.1 \pm 1193.4\left(P<0.05^{* *}\right)$ & $20.0\left(P>0.05^{*}\right)$ \\
Compound 16 & 5 & $3.7 \pm 1.4\left(P>0.05^{* *}\right)$ & $69.4\left(P<0.01^{*}\right)$ & $10094.7 \pm 1691.0\left(P<0.05^{* *}\right)$ & - \\
Compound 20 & 6 & $4.7 \pm 1.1\left(P>0.05^{* *}\right)$ & $61.1\left(P<0.01^{*}\right)$ & $3721.5 \pm 1600.6$ & $53.7\left(P<0.01^{*}\right)$ \\
PZQ & 6 & $3.3 \pm 1.7$ & $72.3\left(P<0.01^{*}\right)$ & &
\end{tabular}

* Effect of compound versus control analysed by Student's t-test; ${ }^{* *}$ Effect of compound versus PZQ analysed by Student's t-test

supposed that the concomitant inhibition of TGR activity would result in the accumulation of reactive oxygen species and increase oxidative stress. However, our NO release and scavenger experiment showed that when compounds $7 \mathrm{c}, 13,16,20$ and 22, and furoxan with a cyano group, were incubated with cysteine, the release of NO increased. When the cyano group of compounds $\mathbf{4 a}$ and $\mathbf{4} \mathbf{b}$ were replaced with a hydroxyl group, no NO release was observed. These results show that the release of NO was related to the cyano group. However compounds 21, 23 and 26 had a cyano group, but did not release NO. Compared with the structure of compounds $7 \mathrm{c}, 13,16,20$ and 22, this may be related to the hydrogen, which was replaced by a benzene ring, influencing the spatial structure of the compounds. Therefore, the release of NO may be relevant to the position of the cyano group in the compound. Compounds 4a, 4b, 7c, 13, 16, 20 and 22 released $\mathrm{NO}$ and the values of their activity against SjTGR were all under $10 \mu \mathrm{M}$. Compounds 19, 21 and 26 did not release NO and neither did they inhibit the SjTGR activity. It appears that the release of NO may inhibit the activity of SjTGR. However, compounds $\mathbf{4 a}$ and $\mathbf{4 b}$ did not release NO, but did strongly inhibit SjTGR, with $\mathrm{IC}_{50}$ values of 2.7 and $1.7 \mu \mathrm{M}$. These results indicate that oxadiazole-2-oxides have other mechanisms against SjTGR activity.

In addition, when the oxadiazole-2-oxides were incubated with SjTGR or worm homogenate for $50 \mathrm{~min}$ at room temperature, no NO release was observed. This illustrates that the relationship between SjTGR inhibition and the release of NO by oxadiazole-2-oxides needs further investigation. Even though compounds $\mathbf{2 3}$ and $\mathbf{2 6}$ did not release NO they had good activity against the worms in vitro; the NO clear experiment showed that there was no difference in the killing activity of the oxiadiazole-2-oxides against the worms in vitro, with or without carboxy-PTIO. This shows that the effects of the drugs against the worms were not correlated with the NO release from the oxiadiazole-2-oxides, indicating that there are other mechanisms, besides $\mathrm{NO}$, that led to mortality of the parasites. That is, the oxadiazole-2-oxides synthesised in this study may have another target, in addition to SjTGR, through which they kill S. japonica.

Our study shows that there were no obvious correlations among the activity of oxadiazole-2-oxides against S. japonicum worms, SjTGR inhibition and the production of NO. One reason for this could be as suggested by Rai et al. [15]; worm death may not occur until the GSH/GSSG ratio reaches a critical point and the overall worm redox balance is unrecoverable, making it difficult to derive correlations between mortality in the worms and TGR inhibition below a certain level. In addition, Treger et al. [32] reported that oxadiazole-2-oxides kill Ancylostoma ceylanicum and proved that their target was not glutathione reductase. Besides these reasons, several studies [33-36] have shown that oxadiazole-2oxides have many functions, which have been used in new drug developments against bacteria, fungi, viruses, worms, tumors, syncopes and immune suppressors. This indicates that oxadiazole-2-oxides may have a lot of function targets. Our study has shown that oxadiazole-2-oxides may have other targets and mechanisms, in addition to SjTGR and its inhibition, within S. japonicum.

\section{Conclusions}

In this study, a series of novel oxadiazole-2-oxides were designed and synthetised. Some of them killed juvenile and adult $S$. japonica effectively. The antischistosomal activity of these compounds was related to their structure, but not positively correlated to the inhibition of SjTGR or NO release. These oxadiazole2-oxides may serve as the leads to develop novel antischistsosomal drugs and explore potential molecular targets further. 


\section{Additional files}

\section{Additional file 1: Procedures for the preparation of compounds. (DOCX $36 \mathrm{~kb}$ )}

Additional file 2: Table S1. Nitric Oxide (NO) production of oxadiazole-2oxides with SjTGR+NADPH or with SjTGR alone, or with worm homogenate supernatant. (DOCX $17 \mathrm{~kb}$ )

Additional file 3: Table S2. Killing activity on juvenile S. japonicum in vitro by oxadiazole-2-oxides. (DOCX $27 \mathrm{~kb}$ )

Additional file 4: Table S3. Killing activity on adult S. japonicum in vitro by oxadiazole-2-oxides. (DOCX $23 \mathrm{~kb}$ )

\section{Abbreviations}

TGR: thioredoxin glutathione reductase; SjTGR: S. japonicum thioredoxin glutathione reductase; DTNB: 5, 5'-Dithiobis-(2-nitrobenzoic acid); NADPH: $\beta$-Nicotinamide adenine dinucleotide 2'-phosphate reduced tetrasodium salt; MTT: 3-(4, 5-dimethyl-2-thiazolyl)-2, 5-diphenyl-2-H-tetrazolium bromide; DMSO: dimethyl sulphoxide; AS: artemisinin; PZQ: praziquantel; carboxy; PTIO: Nitric Oxide Assay Kit and 2 - (4 - carboxyphenyl) - 4, 4, 5, 5 tetramethylimidazoline -1- oxyl - 3 - oxide; EDTA: Ethylenediaminetetraacetic acid; HEPES: 2-[4-(2-Hydroxyethyl)-1-piperazinyl] ethanesulfonic acid; NO: nitric oxide; SD: standard deviation; SAR: structure-activity relationship.

\section{Competing interests}

The authors declare that they have no competing interests.

\section{Authors' contributions}

Designed the experiments: LS, WLW, CXY and BNF. Carried-out the experiments: LS, HL, WHF, GPW, XRY, YJ, WZ, HG, SS, QL and JW. Analyzed the data: $\amalg S$ and WLW. Helped with interpreting results: CXY and BNF. Drafted the manuscript: US, HL and WLW. All authors read and approved the final version of the manuscript.

\section{Acknowledgements}

This work was supported by grants from the National Natural Science Foundation of China (Nos. 30972581, 8120316), the Natural Science Foundation of Jiangsu Province, China (Nos. BK2012544, BK20151120), the Laboratory Research of Parasitic Disease Prevention and Control Platform (No. wk014-002), and Jiangsu Science and Technology Department (No. BM2015024)

\section{Author details}

${ }^{1}$ Key Laboratory on Technology for Disease Prevention and Control, Ministry of Health, Jiangsu Provincial Key laboratory of Parasite Molecular Biology, Jiangsu Institute of Parasitic Diseases, Wuxi, Jiangsu 214064, China. ${ }^{2}$ Public Health Research Center, Jiangnan University, Wuxi 214122, China. ${ }^{3}$ School of Pharmaceutical Science, Jiangnan University, Wuxi 214122, China. ${ }^{4}$ Medical College, Jiangnan University, Wuxi 214122, China.

\section{Received: 7 September 2015 Accepted: 8 January 2016}

\section{Published online: 20 January 2016}

\section{References}

1. Danso-Appiah A, Olliaro PL, Donegan S, Sinclair D, Utzinger J. Drugs for treating Schistosoma mansoni infection. Cochrane Database Syst Rev. 2013;2: CD000528.

2. Gryseels B, Polman K, Clerinx J, Kestens L. Human schistosomiasis. Lancet. 2006;368:1106-18

3. Zheng H, Zhang LJ, Zhu R, Xu J, Li SZ, Guo JG, et al. Schistosomiasis situation in People's Republic of China in 2011. Chin J Schisto Control. 2012; 24:621-6.

4. Wang W, Wang L, Liang YS. Susceptibility or resistance of praziquantel in human schistosomiasis: a review. Parasitol Res. 2012;111:1871-5.

5. Domling A, Khoury K. Praziquantel and schistosomiasis. Chemmedchem. 2010;5:1420-34

6. Patra M, Ingram K, Pierroz V, Ferrari S, Spingler B, Keiser J, et al. Ferrocenyl derivatives of the anthelmintic praziquantel: design, synthesis, and biological evaluation. J Med Chem. 2012;55:8790-8.
7. Dong YX, Chollet J, Vargas M, Mansour NR, Bickle Q, Alnouti Y, et al Praziquantel analogs with activity against juvenile Schistosoma mansoni. Bioorg Med Chem Lett. 2010;20:2481-4.

8. Patra M, Ingram K, Pierroz V, Ferrari S, Spingler B, Gasser RB, et al. (n(6)Praziquantel) $\mathrm{Cr}(\mathrm{CO}) 3$ ] derivatives with remarkable in vitro anti-schistosomal activity. Chemistry. 2013;19:2232-5.

9. Ronketti F, Ramana AV, Chao-Ming X, Pica-Mattoccia L, Cioli D, Todd MH. Praziquantel derivatives I: Modification of the aromatic ring. Bioorg Med Chem Lett. 2007:17:4154-7.

10. Duan WW, Qiu SJ, Zhao Y, Sun H, Qiao C, Xia CM. Praziquantel derivatives exhibit activity against both juvenile and adult Schistosoma japonicum. Bioorg Med Chem Lett. 2012;22:1587-90.

11. Wang ZX, Chen JL, Qiao C. Praziquantel derivatives with antischistosomal activity: aromatic ring modification. Chem Biol Drug Des. 2013;82:216-25.

12. Sadhu PS, Kumar SN, Chandrasekharam M, Pica-Mattoccia L, Cioli D, Rao VJ. Synthesis of new praziquantel derivatives: potential candidates for the treatment of schistosomiasis. Bioorg Med Chem Lett. 2012;22: 1103-6.

13. Ndjonka D, Rapado LN, Silber AM, Liebau E, Wrenger C. Natural products as a source for treating neglected parasitic diseases. Int J Mol Sci. 2013;14: 3395-439.

14. Liu J, Dyer DH, Cheng J, Wang J, Wang S, Yang Z, et al. Aldose reductase from Schistosoma japonicum: crystallization and structure-based inhibitor screening for discovering antischistosomal lead compounds. Parasit Vectors. 2013;6:162.

15. Rai G, Sayed AA, Lea WA, Luecke HF, Chakrapani H, Prast-Nielsen S, et al. Structure mechanism insights and the role of nitric oxide donation guide the development of oxadiazole-2-oxides as therapeutic agents against schistosomiasis. J Med Chem. 2009;52:6474-83.

16. Sayed AA, Simeonov A, Thomas CJ, Inglese J, Austin CP, Williams DL. Identification of oxadiazoles as new drug leads for the control of schistosomiasis. Nat Med. 2008;14:407-12.

17. Liu J, Dyer D, Wang J, Wang S, Du X, Xu B, et al. 3-oxoacyl-ACP reductase from Schistosoma japonicum: integrated in silico-in vitro strategy for discovering antischistosomal lead compounds. Plos One. 2013;8:e64984.

18. Song LJ, Li JH, Xie SY, Qian CY, Wang J, Zhang W, et al. Thioredoxin Glutathione Reductase as a Novel Drug Target: Evidence from Schistosoma japonicum. Plos One. 2012;7:e31456.

19. Harrop R, Wilson RA. Protein synthesis and release by cultured schistosomula of Schistosoma mansoni. Parasitology. 1993;107:265-74.

20. Keiser J. In vitro and in vivo trematode models for chemotherapeutic studies. Parasitology. 2010;137:589-603.

21. Yolles TK, Moore DV, De Giusti DL, Ripsom CA, Meleney HE. A technique for the perfusion of laboratory animals for the recovery of schistosomes. J Parasitol. 1947:33:419-26.

22. Magalhães LG, Kapadia GJ, da Silva Tonuci LR, Ixeta SC, Parreira NA, et al. In vitro schistosomicidal effects of some phloroglucinol derivatives from Dryopteris species against Schistosoma mansoni adult worms. Parasitol Res. 2010;106:395-401.

23. Manneck T, Haggenmüller Y, Keiser J. Morphological effects and tegumental alterations induced by mefloquine on schistosomula and adult flukes of Schistosoma mansoni. Parasitology. 2010;137:85-98.

24. Xiao SH, Mei JY, Jiao PY. The in vitro effect of mefloquine and praziquantel against juvenile and adult Schistosoma japonicum. Parasitol Res. 2009;106: 237-46.

25. Caffrey CR, Secor WE. Schistosomiasis: From drug deployment to drug development. Curr Opin Infect Dis. 2011;24:410-7.

26. Stelma FF, Talla I, Sow S, Kongs A, Niang M, Polman K, et al. Efficacy and side effects of praziquantel in an epidemic focus of Schistosoma mansoni. Am J Trop Med Hyg. 1995;53:167-70.

27. Gasco A, Fruttero R, Sorba G, Di Stilo A, Calvino R. NO donors: Focus on furoxan derivatives. Pure Appl Chem. 2004;76:973-81.

28. Ignarro LJ. Nitric Oxide Biology and Pathobiology. San Diego: Academic; 2000

29. Brunet LR. Nitric oxide in parasitic infections. Int Immunopharmacol. 2001;1: 1457-67.

30. Colasanti M, Gradoni L, Mattu M, Persichini T, Salvati L, Venturini G, et al. Molecular basis for the anti-parasitic effect on NO. Int J Mol Med. 2002;9: 131-4.

31. Rivero A. Nitric oxide: an antiparasitic molecule of invertebrates. Trends Parasitol. 2006;22:219-25. 
32. Treger RS, Cook AG, Rai G, Maloney DJ, Simeonov A, Jadhav A, et al. Oxadiazole 2-oxides are toxic to the human hookworm, Ancylostoma ceylanicum, however glutathione reductase is not the primary target. Int $J$ Parasitol Drugs Drug Resist. 2012:2:171-7.

33. Medana C, Ermondi G, Fruttero R, Di Stilo A, Ferretti C, Gasco A. Furoxans as nitric oxide donors. 4-phenyl-3-furoxancarbonitrile: thiol-mediated nitric oxide release and biological evaluation. J Med Chem. 1994;37:4412-6.

34. Buonsanti MF, Bertinaria M, Di Stilo A, Cena C, Fruttero R, Gasco A. Nitric oxide donor $\beta 2$-agonists: furoxan derivatives containing the fenoterol moiety and related furazans. J Med Chem. 2007;50:5003-11.

35. Turnbull CM, Cena C, Fruttero R, Gasco A, Rossi AG, Megson IL. Mechanism of action of novel NO-releasing furoxan derivatives of aspirin in human platelets. British J Pharm. 2006;148:517-26.

36. Sorba G, Galli U, Cena C, Fruttero R, Gasco A, Morini G, et al. A new furoxan NO-donor rabeprazole derivative and related compounds. ChemBioChem. 2003:4:899-903.

Submit your next manuscript to BioMed Central and we will help you at every step:

- We accept pre-submission inquiries

- Our selector tool helps you to find the most relevant journal

- We provide round the clock customer support

- Convenient online submission

- Thorough peer review

- Inclusion in PubMed and all major indexing services

- Maximum visibility for your research

Submit your manuscript at www.biomedcentral.com/submit
Biomed Central 